\title{
DIREITO DE LAJE: DA IMPORTÂNCIA SOCIAL E DAS CONTROVÉRSIAS QUANTO AO DIREITO DE SUPERFÍCIE E AO CONDOMÍNIO EDILÍCIO
}

\begin{abstract}
Rafael Lamera Giesta Cabral
Doutor em Direito, Estado e Constituição pela Universidade de Brasília - UnB (2016). Mestre em Ciência Política pela Universidade Federal de São Carlos UFSCar (2010) e Bacharel em Direito pela Universidade Estadual de Mato Grosso do Sul - UEMS (2007). Atualmente, é professor adjunto no curso de Direito e no Programa de Pós-Graduação em Administração Pública (PROFIAP Mestrado Profissional) da Universidade Federal Rural do Semi-Árido (UFERSA). É Editor-chefe da Revista Jurídica da Universidade Federal Rural do Semi-árido (REJUR). Desenvolve pesquisas no campo da História do Direito, com ênfase na história constitucional e direitos sociais entre as décadas de 1920 e 1940. Pesquisa também na área de Administração Pública com foco na gestão democrática nos Conselhos Municipais e Gestão de Risco Institucional.

rafaelcabral@ufersa.edu.br
\end{abstract}

\section{Vanessa Dias de Carvalho Quaresma Gama}

Bacharelanda em Direito, pela Universidade Federal Rural do Semi-árido (UFERSA), Mossoró-RN, Brasil.

vanessa_jrpt@hotmail.com

RESUMO: O presente estudo tem como objeto avaliar as concepções do direito de laje como uma política de desenvolvimento e regularização urbana e ao final indicar uma classificação que melhor represente a natureza jurídica desse instituto. A análise do direito de laje foi concretizada a partir dos parâmetros de aplicação dos princípios da dignidade humana, da função social da propriedade e do direito à moradia, a fim de demonstrar seu caráter fundamental de ruptura às clássicas concepções do direito de propriedade. Para que o objetivo fosse alcançado, buscou-se apresentar o percurso legislativo do direito de laje e sua origem na doutrina nacional e internacional. Na sequência foi realizada uma análise detalhada acerca das concepções do direito de laje, especialmente, no tocante ao direito superficiário e ao condomínio edilício, que também guardam similitudes com o instituto. O direito de laje pode ser considerado sui generis, com traços distintos das funções sociais exercidas pelo direito de superfície e condomínio edilício, com forte vocação para a regularização de uma política urbana em aglomerados populacionais.

PALAVRAS-CHAVE: Direito de laje. Regularização urbana. Desenvolvimento. Direito sui generis. 
Direito de laje: da importância social e das controvérsias quanto ao direito de superfície e ao condomínio edilício

The slab law: social importance and controversies regarding the surface law and the building condominium

ABSTRACT: The present study has the objective of evaluating the concepts of the slab right and finally proposing a classification that best represents this institute. The analysis of the right of slab was made based on the parameters of application of the principles of human dignity, the social function of property, the right to housing in order to demonstrate its fundamental character in the environment in which it is inserted. The method used to meet the objective was analyzed by the legislative course undergone by this new law, in addition to its national and international doctrinal origin, allowing to understand the different conceptions of slab. Then, a detailed analysis was carried out on the concepts of slab rights, especially with regard to surface law and the condominium building, which also has similarities with the institute. The right of slab can be considered sui generis that traits different from the social functions exerted by the surface right and condominium building, with strong vocation for the regularization of an urban policy in population groups.

KEYWORDS: Slab right. Urban regulation. Development. Sui generis law.

\section{INTRODUÇÃO}

Em dezembro de 2016, o governo federal lançou a Medida Provisória no 759, que teve por finalidade dispor acerca da regularização fundiária rural e urbana, além de instituir novos mecanismos jurídicos, como a instituição do direito à laje. O rol dos direitos reais, previstos no Código Civil, ganhou mais um instituto, mesmo que criado por uma medida provisória. Por mais que tenha causado estranheza na comunidade jurídica pela forma em que foi concebido o direito de laje, o instituto é vocacionado para uma regulação urbana e rural relevante para a concretização de direitos sociais.

Em julho de 2017, com a promulgação da Lei n. 13.465, o direito de laje passou a ser disciplinado dentro de um projeto mais amplo. Essa lei, contudo, não trouxe os mesmos dispositivos da Medida Provisória $n^{\circ} 759$, pois, antes de integrarem a legislação, fez-se necessário um nítido aprimoramento do conteúdo de alguns artigos, resultando em mais de 700 emendas à referida Medida Provisória, conforme se depreende de Cartilha acerca da Lei de Regularização Fundiária de 2017, elaborada pelo Ministério Público do Estado de São Paulo.

Apesar do seu recém nascimento no direito positivo brasileiro, o direito de laje foi amplamente discutido por juristas e por estudiosos de outras áreas, como os sociólogos, ambientalistas e urbanistas, pois mesmo estando ausente do nosso ordenamento jurídico, a laje é um instituto urbano que existe há décadas no contexto jurisprudencial brasileiro.

A problemática central deste trabalho é promover reflexões sobre a inclusão do direito de laje como um direito real. Essa classificação tornou-se alvo de várias críticas por vários doutrinadores, em virtude da alteração relativa à natureza jurídica desse instituto.

A classificação majoritariamente defendida, fruto dos estudos realizados de grandes juristas nacionais e internacionais, concebia a laje como uma espécie de direito equivalente ao superficiário no ordenamento jurídico brasileiro.

O advento dessa nova legislação atribuiu à laje classificação diversa daquela preconizada anteriormente, ocasionando uma mudança de concepção significativa no instituto ora estudado. 
A partir de uma análise sobre as mudanças geradas por essa regularização, é possível declarar o ensejo à uma ruptura dos modelos sobre o direito de propriedade e seus atributos liberais, forjados no pensamento oitocentista.

Para tanto, abordou-se, na primeira seção, o percurso legislativo estabelecido por esse recente direito, além de sua origem doutrinária nacional e internacional, permitindo compreender as diversas concepções e alcances ao direito de laje. Na segunda seção, promoveu-se uma síntese sobre o problema histórico de moradias (função social) e as necessidades de ampliação políticas de desenvolvimento urbano no país, respaldadas pelos princípios da dignidade da pessoa humana, da função social da propriedade e do direito de moradia.

Na terceira seção, realizou-se uma análise detalhada acerca das concepções do direito de laje, especialmente, no tocante ao direito de superfície, concebido como o que melhor representava a laje pela doutrina majoritária, e ao condomínio edilício que também guarda similitudes com o instituto.

A abordagem metodológica deste trabalho consubstanciou-se no método da investigação histórica-evolutiva, desenvolvida por meio de pesquisa bibliográfica, livros e revistas especializadas, jurisprudências e trabalhos acadêmicos (monografias e teses), com o fito de registrar qualitativamente os diversos institutos que norteiam o direito de laje, bem como o contexto histórico-social ao qual se deu o seu nascimento.

\section{EVOLUÇÃO LEGISLATIVA DO DIREITO DE LAJE}

A previsão legislativa sobre o direito de laje é bastante recente, no entanto, tal direito já foi mencionado por vários doutrinadores em seus estudos. Dentre esses, Rodrigo Mazzei (2007), em sua dissertação de mestrado, já mencionava o direito de laje e era um dos juristas brasileiros que reiterava a urgência em reconhecer este instituto dentro do ordenamento jurídico brasileiro. Nesta seção, aborda-se o avanço legislativo do instituto direito de laje.

O ciclo de desenvolvimento social, político e econômico no Brasil é complexo e quando se voltam para o cenário de ocupação territorial, as soluções apresentadas não dialogam diretamente com uma política pública de regularização urbana e fundiária capaz de concretizar direitos.

Um desses movimentos gerados pelo modelo de desenvolvimento brasileiro foi o surgimento das favelas, marcadas, na história, especialmente como uma das consequências do desordenado desenvolvimento urbano, que se associa, comumente, ao instituto imobiliário das lajes.

Uma das políticas públicas a serem implementadas deve ser o reconhecimento de que o surgimento das favelas são fatos sociais, sendo assim, um fomentador de mudanças também no âmbito legal. Dessa forma, concebe-se que a regularização de direitos que atendam a demanda social dos habitantes desse instituto urbano é indispensável.

Uma das questões acerca dessa regularização a ser abordada é a instrumentalização do direito de laje no âmbito favelar, mais especificamente pela evidência recorrente da prática de alienação, gratuita ou onerosa das lajes de suas propriedades, por moradores dessas comunidades, para que terceiros lá construam ou residam, conforme destaca Magno de Oliveira (2014).

Diante disso, apesar da necessidade de normatizar o direito relativo ao ambiente favelar, é incomum sua expressa previsão legislativa no âmbito legislativo internacional, tornando o 
Direito de laje: da importância social e das controvérsias quanto ao direito de superfície e ao condomínio edilício

Brasil um verdadeiro vanguardista com a promulgação desta legislação, que tem por objetivo regularizar imóveis em regiões de favela.

O que existe há tempos nos ordenamentos estrangeiros, como o português e suíço, são interpretações doutrinárias acerca desse direito com base em legislações que tratavam sobre o uso do espaço aéreo das propriedades, tal como a laje era disciplinada no direito brasileiro antes da MPV no 759/2016.

Por outro lado, conforme Sarmento Filho (2012), não há unanimidade em relação a natureza jurídica lajeária. Observando-se que grande parte dos ordenamentos jurídicos alienígenas trata a laje como um desdobramento do direito de superfície, referindo-se a ela comumente como sobrelevação ou, como no direito suíço, superfície em segundo grau. Todos esses institutos estão presentes na doutrina brasileira, contudo com algumas distinções quanto à natureza jurídica, que serão futuramente abordadas (LOUREIRO, 2017).

Dito isto, é possível contemplar, nesse instituto, três níveis de propriedade: a do dono do solo, a do primeiro superficiário e a do segundo superficiário (AMARANTE, 2012). Esse fenômeno jurídico relaciona-se com o direito de laje de forma independente ao qual é atribuído à propriedade objeto de uma superfície em segundo grau, já que o segundo superficiário cria uma nova propriedade desvinculada em relação à propriedade de origem. Esse fato é frequente em diversas comunidades periféricas, decorrentes das construções de "puxadinhos", desvinculados do prédio principal, a fim de vendê-los a terceiros.

No Código Civil lusitano de 1966, por exemplo, é possível notar a mesma ausência de menção expressa do termo direito de laje que o ordenamento brasileiro lidava antes da MPV $\mathrm{n}^{\circ}$ 759/2016, contudo a figura da sobrelevação estava inserida, como dispunha em seu Art. 1.52.

A partir desse dispositivo, percebe-se a presença da influência do direito de superfície na propriedade horizontal, incomum na realidade social brasileira, mas que foi uma das fontes para a elaboração do dispositivo brasileiro que trouxe as primeiras formas para a aplicação do direito de superfície aos espaços aéreos contido no Estatuto da Cidade, em 2001 (Lei n. 10.257).

É relevante salientar que o direito de sobrelevação não foi apenas apresentado pelo direito português, mas já podia ser observado tanto na legislação italiana quanto na suíça (PEREIRA, 2014), com normatividades próprias.

Diante de uma breve análise sobre esses ordenamentos jurídicos, é possível reconhecer a existência de figuras primitivas do direito lajeário. Grande parte delas relacionadas com institutos equivalentes com o direito de superfície, com as particularidades de cada Estado.

Em um primeiro momento, o Brasil teve influências desses ordenamentos para reger o seu próprio direito de superfície, que atendia às demandas sociais pela regularização da laje, na ausência de uma legislação própria.

\subsection{Primórdios do direito de laje brasileiro}

A doutrina começou a se debruçar acerca do assunto e realizar as primeiras tentativas na delimitação de sua natureza jurídica e seus fundamentos após alguma previsão no ordenamento jurídico que permitisse a interpretações nesse sentido.

Conforme entendimento de Cristiano Chaves de Farias (et. all., 2017), Ricardo Pereira Lira (2012) e Rodrigo Mazzei (2012), a maior representação do direito favelar antes de sua 
previsão expressa estaria presente no Estatuto da Cidade de 2001, mais especificamente em seu art. $21, \S 1^{\text {o }}$, que dispõe sobre a abrangência do direito de superfície, classificação comumente atribuída à laje antes da regularização legislativa. Tal dispositivo expõe o rol de objetos de concessão do direito superficiário para além do solo, subsolo e o espaço aéreo relativo ao terreno.

Em razão de ser a primeira menção ao direito de usar o espaço aéreo de um terreno, por muito tempo a doutrina brasileira defendeu majoritariamente a concepção de laje como um direito de superfície.

Naturalmente, em virtude de o legislador não ter previsto de maneira expressa o direito de laje e muito menos sua vedação legal, essa adaptação interpretativa se tornou a regulação da sobrelevação brasileira, um instituto que, como se pode analisar anteriormente, adveio do direito estrangeiro, na qual trazia as bases para esse projeto de regularização do direito lajeário. Contudo, com a regularização do direito lajeário, juristas reanalisaram o instituto, afirmando que "a intenção do legislador não era a de possibilitar a cessão da superfície do imóvel já construído, já que a utilização do espaço aéreo se direcionava unicamente ao terreno" (FARIAS, et. all., 2017, p. 28).

Esse entendimento inviabiliza diversas situações como a própria laje, pois se infere a limitação e restrição da concessão superficiária, assunto que será aprofundado em momento oportuno. Ademais, percebe-se a importância dessa classificação puramente doutrinária a fim de formar verdadeira base para a elaboração das legislações que surgiram com a regularização da situação lajeária.

A concepção de laje como um direito de superfície foi imprescindível para a construção do que se tem hoje do instituto. É relevante esclarecer que, com a Lei 13.465/17, o direito de laje ganhou nova classificação.

Neste aspecto, há uma nítida inspiração no direito de superfície, especialmente no que tange o art. 21, parágrafo primeiro, da Lei 10.257/2001, já comentado acima. No entanto, com ele não se confunde, uma vez que opor-se-ia uma interpretação restritiva do instituto.

Não obstante, é importante ressaltar que não devem ser confundidas essas concepções advindas do art. $21, \S 1^{\circ}$ do Estatuto da Cidade de 2001 com a concepção trazida pelas novas legislações acerca do assunto. Elas são apenas os moldes primitivos para o direito de laje atual.

\subsection{O percurso legislativo do direito de laje: Da MPV no 759/2016 à Lei}

\section{$13.465 / 2017$}

Após esse momento de obscuridade legislativa acerca do direito de laje, em que imperava a interpretação dos juristas brasileiros com base em menções normativas à concessão do uso do espaço aéreo de terrenos, os legisladores reuniram esforços para elaborar uma legislação que inserisse o direito favelar efetivamente no ordenamento jurídico nacional.

A MPV no 759 não dispôs apenas sobre a novidade do direito de laje, ela destinou-se à regularização de algumas situações fundiárias urbana e rural, inclusive no âmbito da Amazônia Legal.

Segundo a MPV no 759/2016, o direito de laje consistiria na "possibilidade de coexistência de unidades imobiliárias autônomas de titularidades distintas situadas em uma mesma 
Direito de laje: da importância social e das controvérsias quanto ao direito de superfície e ao condomínio edilício

área, de maneira a permitir que o proprietário ceda a superfície de sua construção a fim de que terceiro edifique unidade distinta daquela originalmente construída sobre o solo".

A Medida Provisória acima citada ainda trouxe uma noção dos efeitos que legislador queria gerar socialmente, todavia é perceptível que o capítulo que dispõe acerca da laje necessitava de algumas modificações, pois alguns dispositivos tinham uma redação confusa.

A título de exemplo, um dos dispositivos em que era possível perceber uma dificuldade interpretativa e até uma certa incoerência com o instituto estava incorporado ao $\S 1^{\circ}$ do Art. 1.510-A, no que se refere à impossibilidade de individualização de lotes, a sobreposição ou a solidariedade de edificações ou terrenos.

Posteriormente à promulgação da MPV nº 759/16, a legislação retornou à Câmara dos Deputados e ao Senado Federal para novas discussões que duraram muitos meses, resultando a publicação da Lei 13.465, em 11 de julho de 2017, após 732 emendas legislativas.

Nessa legislação, foi possível perceber não apenas a reforma total da redação dos dispositivos da MPV 759/16, como também algumas novidades sobre o registro da laje que, embora tenha sido mencionado na medida provisória, ganhou mais destaque e foi consideravelmente ampliado.

Na Lei 13.465/17, há mais harmonia na compreensão do instituto, além de uma redação mais clara dos seus dispositivos. O conceito de laje modificou-se também. A novidade desse conceito para o previsto na MPV n ${ }^{\circ} 759 / 16$ foi a especificação quanto à restrição do que pode ser contemplado pelo direito de laje, que foi de grande importância para a distinção do direito de laje aos outros institutos, como o direito de superfície e condomínio edilício.

Ao longo desse trabalho far-se-á uma análise mais profunda sobre os dispositivos dessa lei, além de adentrar no estudo dos princípios que norteiam esse novíssimo direito.

\section{FUNDAMENTOS NORTEADORES DO DIREITO À LAJE}

A laje, apesar de sua recente regularização, está presente na realidade social brasileira desde seus primórdios históricos quando a influência política portuguesa ainda era evidente sobre o Brasil.

O instituto lajeário encontra referências até mesmo na literatura nacional, como é possível analisar na obra prima "O Cortiço", de Aluísio de Azevedo (1890), que, mesmo sendo uma ficção literária, retrata bem a vivência marginal dos moradores de construções irregulares no Rio de Janeiro, no final do século XIX.

Há claras alusões ao instituto da laje inseridas na ambientação desse clássico literário. Uma dessas referências apresenta-se no seguinte trecho:

\footnotetext{
O que aliás não impediu que as casinhas continuassem a surgir, uma após outra, e fossem logo se enchendo, a estenderem-se unidas por ali a fora, desde a venda até quase ao morro, e depois dobrassem para o lado do Miranda e avançassem sobre o quintal deste, que parecia ameaçado por aquela serpente de pedra e cal (AZEVEDO, 1890. p. 6).
}

Não é difícil verificar no romance a semelhança com as favelas brasileiras, especialmente no tocante ao caráter irregular da construção, sem mencionar a condição social marginalizada das personagens que habitavam o cortiço/favela de João Romão. 
Nesse quadrante, é interessante notar que essa obra não gira em torno apenas do modo de vida daqueles que habitavam nos cortiços da época, mas também retrata o movimento urbano pelo qual o Rio de Janeiro estava passando.

Esse romance espelhou um futuro próximo, como o período da reforma urbanística promovida por Pereira Passos, entre 1902 e 1906, com a finalidade de modernizar o Rio de Janeiro, controlando a propagação de doenças e pestes que assolavam a cidade, além de aprimorar o tráfego (SUPPIA e SCARABELLO, 2014). Contudo, outra medida dessa reforma atingiu diretamente a população trabalhadora que habitava nos cortiços, consistindo na demolição de diversas moradias.

Em razão disso, a reforma que tinha como finalidade "modernizar" a cidade findou-se por transferir o "problema" de lugar, tornando-se uma das responsáveis pelo surgimento das favelas nos morros cariocas, pois os moradores dos cortiços do centro da cidade se mudaram para as periferias, formando os subúrbios favelados como são conhecidos atualmente.

Ainda que a obra seja ficcional, não se deve desconsiderar o movimento literário em que se insere. Sendo um dos clássicos naturalistas nacionais, sua essência deve-se basear na observação fiel da realidade e na experiência (GUINSBURG, 2017), tornando-a um referencial histórico-social da época em que foi elaborada.

Desse modo, a partir da análise da retratação histórica-social da época e realizando uma breve comparação entre as unidades que compõem a estalagem do protagonista da história e as lajes das favelas brasileiras, pode ser afirmado que a laje é presente na realidade brasileira pelo menos desde o século XIX.

Naturalmente, a referência do instituto lajeário na literatura brasileira é apenas uma evidência da sua existência desde da instauração da república na história nacional. Apesar disso, como se analisará a seguir, seu surgimento na realidade social é até mesmo anterior à publicação desse icônico romance tupiniquim. A questão ocupacional e o abismo entre a classe opressora e oprimida marca a história brasileira desde a colonização lusitana, perdurando e crescendo até os dias atuais.

É interessante que uma das marcas dessa divisão social estava intimamente ligada ao aspecto da moradia, pois enquanto os dominantes habitavam a casa grande, os escravos viviam em senzalas, inferindo, desse modo, a condição habitacional como um dos externadores da desigualdade social presente na época em que estava inserida.

Mesmo com a abolição da escravidão no Brasil, a distância social entre ex-senhores de escravos e ex-escravos não foi atenuada. Os escravos recém-libertos "das cidades coloniais passaram por novos desafios com o advento da cidade republicana, a qual foi construída visando aos interesses da aristocracia dominante à época" (GARCIA apud AMARANTE, 2012, p. 4).

Conforme Cláudia Franco Correa (2008), o fim da escravidão e a proclamação da república trouxe mudanças bastante significantes no cenário demográfico brasileiro e, ainda,

\begin{abstract}
[...] com o fim da escravidão cresceu o número de desempregados e subempregados, pela quantitativa mão de obra lançada no mercado sem condições de absorvêla. Um grande êxodo ocorre proveniente da região cafeeira do estado do Rio, associado ao processo de aumento da presença estrangeira, de modo especial, os portugueses. Na primeira década da República a população quase dobrou (CORREA, 2008, p. 998).
\end{abstract}

Nota-se, nesse trecho, os dois primeiros fatores para o crescimento populacional urbano brasileiro, o êxodo rural e o aumento de estrangeiros no país. O súbito aumento populacional 
Direito de laje: da importância social e das controvérsias quanto ao direito de superfície e ao condomínio edilício

sem planejamento estrutural torna a questão habitacional um grave problema a ser solucionado pelo Estado.

Entretanto, como pode-se observar na atual conjuntura político-econômica em que o país se encontra, a falta de investimentos e o reduzido planejamento do Estado na ampliação da infraestrutura urbana contribuiu para a formação de uma construção marginal nas cidades, ou seja, o surgimento de favelas.

Com o crescimento populacional desordenado, aqueles que possuem melhores condições financeiras são os poucos capazes de garantir moradias dignas, enquanto a população menos favorecida economicamente é vítima desse movimento urbano, o qual a força a se aglomerar em edificações irregulares e geralmente sem qualquer infraestrutura (TESHIMA, 2013).

Ignorar a realidade dos grandes aglomerados urbanos que se organizam em moradias irregulares, como "puxadinhos", ou que promovem múltiplas divisões de uma pequena propriedade que não alcança 100 metros quadrados, é violar os princípios da dignidade humana, da função social da propriedade ${ }^{1} \mathrm{e}$ do próprio direito constitucional à moradia.

Conforme visto anteriormente, a segregação social é a grande fomentadora do surgimento e crescimento das favelas e da laje no âmbito brasileiro. Não obstante, o distanciamento entre os mais e menos favorecidos economicamente não é o efeito mais grave da desigualdade social, desencadeando diversos outros efeitos.

Boaventura de Sousa Santos (1973), em sua tese de doutorado sobre a pluralidade jurídica existente em um mesmo espaço geopolítico, fala sobre a possibilidade de acepção de um direito além do direito do Estado, ao qual ele denominou de "direito de asfalto".

Nessa tese, ele disserta sobre a criação de um ordenamento jurídico para suprir as necessidades de determinado grupo, que teoricamente deveria ser composto pela totalidade dos cidadãos de um Estado. Todavia, esse grupo não abrange aqueles invisíveis à sociedade.

$\mathrm{O}$ direito do Estado se torna insuficiente para aqueles que vivem à margem da sociedade, em virtude da nítida negligência do Poder Público acentuada pela omissão social, que os compele a estabelecer um direito próprio que atenda às demandas desse grupo (SANTOS, 1973).

Ao analisar essas comunidades, percebe-se que elas têm um representante que é reconhecido como um verdadeiro líder político, diferente dos líderes políticos eleitos legitimamente pelo povo. Do mesmo modo ocorre com o Poder Judiciário, que muitas vezes não é usufruído pelos habitantes dessa comunidade por diversos fatores. Um deles é a convicção de ser inútil e perigoso.

Era inútil porque "os tribunais têm que seguir o código e pelo código nós não tínhamos nenhum direito". Era perigoso porque "trazer a situação ilegal da comunidade à atenção dos serviços do Estado poderia levá-los a nos jogar na cadeia” (SANTOS, 1973, p. 8).

Percebe-se que os próprios indivíduos inseridos nessas comunidades se consideram em uma situação ilegal em razão da irregularidade da habitação, "como se a legalidade da posse da terra se repercutisse sobre todas as outras relações sociais, mesmo sobre aquelas que nada têm a ver com a terra ou com a habitação" (SANTOS, 1973, p. 8).

1 Para maiores detalhes ver Pessoa (2010) e Damacena; Webber (2016). 
Todo esse status ilegal é reforçado ainda mais pela previsão legislativas inexistente sobre os institutos que formam a comunidade favelada. Entretanto, insurgiram diversos movimentos sociais que auxiliaram no processo de evidência dessas comunidades faveladas.

Há registros de movimentos sociais advindos de organizações comunitárias desde o início do século XX, naturalmente, com diversas demandas, mas todas voltadas para a conquista de melhorias estruturais no espaço marginal e na efetivação do direito pleno à moradia (OLIVEIRA, 2014).

É notável que os diversos movimentos sociais e associações originadas das bases faveladas foram elementos cruciais e de suma importância não apenas para a recente regularização da laje como um direito real, mas também para a contribuir na redução da distância social entre as classes sociais.

\section{CONTROVÉrsias CONCEITUAIS ACERCA DO DIREITO DE LAJE}

A falta de previsão normativa acerca do instituo da laje estimulou diversos juristas a buscar dar formas a esse possível direito. Antes da publicação da Lei 13.465/17, a doutrina majoritária defendia uma classificação de direito de laje diferente da classificação a ela atribuída na nova legislação.

Essa seção se dedicará a explorar as concepções do direito lajeário e as interpretações do conceito trazido pela Lei 13.465/17, além de analisar qual seria o conceito que melhor retrata e satisfaz os efeitos e necessidades dos habitantes dessa modalidade imobiliária.

O primeiro ponto de partida é que o direito de superfície era comumente relacionado ao direito de laje pelos juristas brasileiros e internacionais. Sabe-se que o direito de superfície está previsto no ordenamento jurídico brasileiro em duas legislações distintas, o Estatuto da Cidade (2001) e o Código Civil (2002).

Contudo, o Código Civil de 2002 amplia a possibilidade de aplicação do direito de superfície, destinando-se a áreas tanto urbanas quanto rurais, enquanto o direito superficiário no Estatuto da Cidade de 2001 restringe-se a contemplar apenas o ambiente urbano.

De outro giro, consoante inteligência do art. 1.225, II, do Código Civil de 2002, o direito de superfície está inserido no rol de direitos reais. A previsão do instituto no Estatuto da Cidade não oferece nenhuma incongruência que prejudique a autenticidade dessa vinculação.

Apesar da ausência de pontos controvertido entre os dispositivos relativos ao direito de superfície das duas normas legais, a lei n. 10.275/2001 traz aspectos não mencionados pelo Código Civil, de 2002, alargando, por exemplo, os objetos de concessão desse direito. Como visto, anteriormente, ultrapassando a possibilidade de uso do solo, inserindo o uso do subsolo e do espaço aéreo relativo ao imóvel (Art. 21, $\$ 1^{\circ}$ do Estatuto da Cidade, de 2001) no rol de hipótese abrangidas pelo direito de superfície. Entretanto, o Código Civil de 2002 preferiu por restringir esse rol, em seu parágrafo único do Art. 1.369, não autorizando obra no subsolo, salvo se for inerente ao objeto da concessão.

É nítida a omissão do Código Civil quanto à utilização do espaço aéreo relativo ao imóvel, dando azo à doutrina se manifestar sobre a coerência do uso de uma interpretação extensiva ao dispositivo mencionado acima.

Conforme dispõe Lira (2002b, p. 252), o direito de superfície "é um [direito] real sobre a coisa alheia autônomo", autonomia esta traduzida em desvinculação com o terreno ou a pro- 
Direito de laje: da importância social e das controvérsias quanto ao direito de superfície e ao condomínio edilício

priedade base, atribuindo um caráter mais independente a essa espécie de direito real sob coisa alheia, pois cria "uma propriedade dentro de outra propriedade", ultrapassando os "contornos clássicos" da propriedade, abrindo um leque de novas alternativas.

A interpretação desse grande jurista, porém, contém inconsistências, tendo em vista a clara impossibilidade de desvinculação da área dada em concessão superficiária, em relação ao terreno em que está inserida.

A partir de uma breve análise da própria natureza jurídica do instituto de concessão de uso de bens cuja essência é posse de um bem, e não o domínio, a superfície dada em concessão guarda, invariavelmente, certa dependência em relação a propriedade base (BERNARDI, 2006).

Ademais, apesar desse embaraço doutrinário, deve-se desconsiderar, incontestavelmente, a possível confusão entre o instituto da laje e o direito de superfície lato sensu, em razão da laje consistir na existência de unidades imobiliárias autônomas de titularidades distinta da construção base (CAMARGO, 2017), inexistindo dependência entre os institutos.

Além disso, conforme disserta Camargo (2017) é indispensável a existência de alguma edificação sobre o solo para configurar uma laje, na forma da Lei n. 13.465/17, enquanto, o direito de superfície pode se referir apenas a terreno sem necessidade de benfeitoria alguma.

\subsection{Superfície por cisão, subsuperfície e sobrelevação}

A constituição do direito de superfície por cisão passou a ser admitida no ordenamento jurídico brasileiro a partir dos apelos do Enunciado no 250 do Conselho da Justiça Federal, na III Jornada de Direito Civil. É um instituto sobre o qual guarda bastante semelhança com o direito de laje. O superficiário por cisão integra em seu patrimônio a acessão já existente no imóvel da concedente, esteja esta finalizada ou não por determinado tempo (PEREIRA, 2014, p. 19).

Dessa forma, observa-se, em suma, que a superfície por cisão ocorre quando o proprietário do solo constrói ou planta em seu terreno; no entanto, transfere a um superficiário o direito de manter essa construção ou plantação. Assim, "o superficiário tornar-se-á proprietário da construção ou plantação, e o dono do terreno continuará na propriedade deste" (FERRARO, 2005, p. 137).

Essa espécie superficiária destoa do direito de superfície, pois essencialmente o direito de superfície restringe-se à concessão e não à alienação, como ocorre na superfície por cisão. $\mathrm{O}$ direito de laje guarda similitude com esse tipo de direito em razão dessa possibilidade de transferência.

Em contrapartida, Farias (et. all., 2017) defende que, no tocante à superfície por cisão, não há previsão de uso do espaço aéreo, mas sim sobre a possibilidade que se construa sobre o terreno já edificado ou plantado, restando equivocada a comparação com o direito de laje, apesar da possível semelhança prática dos institutos.

Ao lado destas questões, também há a sobrelevação originada da concessão do "direito de construir um novo andar sob uma construção já erguida, passando o superficiário a ser proprietário do implante" (PEREIRA, 2014, p. 50), configurando, assim, uma espécie de condomínio edilício. 
Esse instituto do direito de superfície era ponto de referência forte do direito de laje, fundamentando pesquisas de diversos juristas como Mazzei (2012) e Amarante (2012), mas ele não está previsto no nosso ordenamento jurídico, sendo controversa sua admissão pela doutrina, e, consequentemente, divergente o surgimento de direito de laje em um instituto que não está inserido no sistema legal.

Ademais, Farias (et. all., 2017) acredita que mesmo sendo um instituto superficiário encabeçado pela doutrina urbanística, possui limitações ao direito de laje que não abarcam todas as situações jurídicas que os legisladores têm o intuito de tutelar, além de não gerar a segurança jurídica para os destinatários desse novo direito.

De outro quadrante, é importante analisar que a promulgação da Lei n. 13.465/17, que disciplina o direito de laje, era também voltada para a regularização de diversas situações urbanas, ganhando, dessa forma, o caráter de instrumento de efetivação de políticas urbanas, assim como o Estatuto da Cidade.

Ora, a partir da regularização da laje no direito urbanístico, pode-se afirmar que ela contempla as situações práticas pertencentes a esse meio ambiente artificial, não excluindo a possibilidade de aplicação da superfície por cisão ou da sobrelevação em caráter residual, voltando-se, por exemplo, para a realidade rural.

Dessa forma, mesmo que a superfície por cisão e a sobrelevação possuam semelhanças práticas com o direito de laje, torna-se nítido o objetivo do direito lajeário em auxiliar no cumprimento das políticas de direito urbano, enquanto os demais institutos não possuem essa mesma vinculação. Sendo assim, é perfeitamente possível a existência simultânea desses institutos no direito brasileiro.

De outro giro, apesar da coerência entre os núcleos das concepções de direito de superfície entre as supracitadas legislações, é importante observar outra diferença significativa entre elas, in casu, a fixação do prazo de concessão (TARTUCE, 2016).

Conforme prevê o Estatuto da Cidade de 2001, a concessão pode ser feita por tempo determinado ou indeterminado, como é possível analisar expressamente em seu artigo 21.

Por outro lado, o art. 1.369 do Código Civil de 2002, posterior à Lei n. 10.275/2001, prevê de forma expressa a concessão desse direito apenas por tempo determinado, restringindo a um direito de caráter temporário.

Segundo Mazzei (2012), é necessário notar que, mesmo ocorrendo essa diferença entre essas disposições do Código Civil e do Estatuto da Cidade, os legisladores não permitiram a possibilidade de um direito de superfície perpétuo. Apesar disso, mesmo sendo inerente ao direito de superfície o caráter temporário, Mazzei (2012) aponta a ausência de prévio ajuste contratual de prazo e a falta de estipulações nas legislações de um prazo padrão de duração contratual um risco de violação da função social da propriedade e do contrato de concessão, além de desvirtuar um dos aspectos essenciais do instituto.

Analisando essa temporalidade da concessão do direito de superfície sob uma interpretação jurídica que respeita a realidade em que a sociedade está inserida, percebe-se a incompatibilidade com o direito de laje, pois torna a laje um instituto limitado em relação aos efeitos práticos buscados pelos habitantes dessas construções urbanas.

Todavia, é importante atribuir ao direito de superfície uma classificação primitiva do direito de laje. A lei n. 13.465/17, trouxe uma classificação única sobre o instituto, aperfeiçoando as concepções doutrinárias sobre o tema. 
Direito de laje: da importância social e das controvérsias quanto ao direito de superfície e ao condomínio edilício

\subsection{Aspectos do condomínio edilício comparados com o instituto lajeário}

Um instituto do direito real bastante semelhante com a espécie lajeária é o condomínio edilício, que também está inserido no Código Civil de 2002. Com base no art. 1.331 do Código Civil, pode-se afirmar que o condomínio edilício é composto por múltiplas unidades autônomas, de uso exclusivo, isoladas entre si com destinação residencial ou não e áreas comuns (FRANCESCHET, 2007).

Depreende-se desse dispositivo a presença simultânea de áreas privativas e de áreas comuns, caracterizando o condomínio edilício horizontal. Por ser composto de unidades múltiplas autônomas, há certa aproximação com o instituto lajeário, gerando confusões acerca da distinção entre esses institutos.

Como preleciona Stolze (2017), para se configurar o instituto imobiliário urbano favelar é necessária a observação de alguns aspectos. Um deles é o "isolamento funcional", inferindose indispensabilidade de destinação independente da construção-base.

Nesse aspecto, resta clara a semelhança entre os dois institutos, em razão de ambos abrangerem a possibilidade de conter unidades autônomas e livres destinações. Contudo, o outro aspecto apresentado por Stolze (2017) necessário para se configurar uma laje é o "acesso independente", previsto no $\S 3^{\circ}$ do art. 1.510-A, ou seja, será indispensável a construção de um meio de acesso ao imóvel lajeário ao qual terá uso privativo do proprietário da laje. Ademais, além do $\S 1^{\circ}$ do art. 1.510-C da lei n. 13.465/17 trazer bastantes semelhanças com o art. 1.331, $\S 2^{\circ}$, do Código Civil que determina as áreas comuns dos condomínios edilícios, nota-se, em seu caput, a possibilidade de aplicação subsidiária das regras do condomínio edilício ao direito de laje, gerando nítida confusão entre os institutos.

Consoante leitura de Farias (et. all., 2017, p. 34) acerca dessa ambiguidade entre os institutos, acredita-se que "o condomínio edilício cria uma complexa relação entre propriedade exclusiva e propriedade comum, muito mais densa e firmada sobre o direito de laje".

Segundo Camargo (2017), o condomínio edilício possui diversos aspectos únicos que destoam do instituto lajeário, como a necessidade de vinculação da unidade autônoma com uma fração do solo ao qual o condomínio está edificado. Defendendo a distinção entre os respectivos institutos, o referido autor aduz também que seria "inconcebível, por exemplo, a nomeação de um síndico para representar o interesse das partes, igualmente inaceitável a existência de cobrança compulsória de contribuição condominal” (CAMARGO, 2017, p. 4).

Ainda, deve-se ressaltar que a laje não se apresenta como uma simples mescla de propriedade comum e propriedade autônoma ou individual. Faz-se imprescindível uma interpretação teleológica acerca da lei n. 13.465/2017 para compreender que ela se destina a regularizar situações concretas e é voltada ao atendimento das demandas de um grupo de indivíduos geralmente com limitados recursos financeiros.

Em razão dessa finalidade social, não é coerente impor aos habitantes lajeários os encargos da implementação de condomínios edilícios, pois, naturalmente, requer um custo maior a ser despendido por eles.

Levando em consideração tudo que foi exposto sobre o condomínio edilício e a laje, apesar da superficial semelhança prática entre os institutos imobiliários, não há razões para relacioná-las. 


\subsection{O direito de laje como um direito sui generis}

Diante das considerações anteriores acerca de institutos relacionados à laje antes da promulgação da lei n. 13.465/2017, resta cristalino afirmar que nenhum dos institutos estudados atende às demandas específicas às quais o instituto lajeário depreende. ${ }^{2}$

Em virtude dessa ausência de adequação perfeita da laje entre os institutos do direito real já concebidos, o legislador foi impelido a criar uma espécie de direito real que tentasse abranger todos os aspectos jurídicos e sociais trazidos por esse tipo de moradia tão singular.

Esse esforço legislativo é digno de mais reconhecimento, não só por dar visibilidade e importância social a um grupo marcado pela negligência do Poder Público, mas também por estar um passo a frente de diversos países que se limitam às interpretações doutrinárias para disciplinar tal instituto.

A lei n. 13.465/2017 trouxe uma nova perspectiva acerca do assunto, atribuindo à laje um caráter de direito autônomo, constituindo um novo tipo de propriedade, assim como disserta Farias (et. all., 2017).

Outrossim, a partir da análise realizada sobre os institutos relacionados à laje no direito de superfície, percebe-se que eles nunca iriam abarcar todos as expectativas de efeitos que a população favelar busca com o reconhecimento desse direito.

Consoante Farias (et. all., 2017), os defensores da perspectiva que reconhece o direito de laje como uma espécie de direito de superfície estão submetendo o direito de laje à uma limitação de sua funcionalidade própria, reduzindo a laje à uma natureza acessória.

Um dos efeitos práticos do reconhecimento da laje como um instituto sui generis, autônomo e independente é a impossibilidade de registro duplo em um só imóvel, defendido pela concepção superficiária da laje. $\mathrm{O}$ caráter autônomo do instituto lajeário prima pela necessidade de registro da laje como unidade distinta da construção-base constituída de matrícula própria como aduz o art. 1.510-A, $\S 3^{\circ}$ da referida lei, tornando-a uma propriedade plena.

Além do registro imobiliário independente, outro efeito singular da laje é a possibilidade a possibilidade do lajeário usar, fruir e dispor livremente da laje, conferindo ao proprietário do imóvel em estudo poderes incompatíveis a quem se encontra em uma situação de subordinação.

Dessa forma, depreende-se a laje é um instituto único e que não deve ser reduzido para se adequar a outros institutos que não só os limitaria, mas desvirtuaria o propósito da sua regularização.

De outro giro, em virtude dos poucos dispositivos que a regularizam, não foi exaurido em lei todos os efeitos do reconhecimento do direito de laje. Farias (et. all., 2017), já apresentou alguns desses possíveis efeitos como o trânsito jurídico regularizado e a dação em garantia real do direito de laje.

Nesse ínterim, cumpre ressaltar a nítida potencialidade do instituto, especialmente pela amplitude das garantias dadas ao lajeário em usar, gozar, dispor dessa propriedade autônoma.

Em suma, deve-se ressaltar que essa legislação atribui ao instituto lajeário natureza jurídica de direito real autônomo, distanciando-se da natureza acessória doutrinária ao qual era comumente associada.

2 Sobre os desafios na indeterminação de conceitos e instituto jurídicos ver Marisa Vila (2018). 
Direito de laje: da importância social e das controvérsias quanto ao direito de superfície e ao condomínio edilício

Além disso, já é possível vislumbrar contribuições significativas dessa classificação inovadora, como a matrícula própria e independente de inúmeras lajes, concedendo não apenas o caráter legal, bem como a regularidade dos negócios jurídicos advindos do registro imobiliário do instituto.

\subsection{Efeito jurisprudencial do direito de laje}

Após considerações acerca da acepção mais coerente com o instituto lajeário, faz-se necessário um estudo sobre os efeitos práticos jurisprudenciais trazidos por essa nova legislação.

Ora, com a recente atribuição de direito real pleno ao direito de laje, resta clara a possibilidade de configurar objeto de ação judicial.

Nesse ínterim, esse entendimento de garantia de meios aquisitivos judiciais para habitantes do instituto lajeário foi recentemente reconhecido jurisprudencialmente pelo Juízo de uma das varas cíveis da comarca de Recife/PE, em sentença publicada em 14 de julho de 2017 (AFFE, 2017).

Em pronunciamento ao sítio eletrônico do Instituto de Registro Imobiliário do Brasil (2017), o Juiz de Direito Rafael José de Menezes, responsável pela referida sentença, comentou sobre a subsunção do direito de laje para dirimir duas ações de usucapião trazidas a lume, sendo que em uma delas, a parte autora requeria usucapião da parte de baixo de uma casa; e na outra, a filha da parte autora do processo anterior pedia usucapião da parte de cima.

É possível declarar que mesmo sob o tratamento doutrinário reputado à laje antes da promulgação da lei n. 13.465/2017, já era possível a garantia dos direitos reivindicatórios por meio de ações próprias de direitos reais limitados, in casu, o direito de superfície. Todavia, com essa regulamentação própria que atribui a laje natureza real plena, permite-se ser objeto legal de ações judiciais.

Ademais, ressalta-se que mesmo com o amparo doutrinário a favor da tutela judicial de tal direito, não havia jurisprudências sobre o tema em virtude da ausência de qualquer previsão legal do instituto, gerando o inevitável sentimento de insegurança jurídica aos lajeários.

Hoje, com a devida previsão legal, já é possível contemplar a primeira jurisprudência sobre a laje tutelada pelo ordenamento jurídico brasileiro.

\section{CONSIDERAÇÕES FINAIS}

$\mathrm{O}$ instituto direito à laje foi inserido no ordenamento jurídico mediante uma Medida Provisória. A estranheza pela forma como o instituto foi inserido no Código Civil brasileiro foi logo percebido por grande parte dos doutrinadores nacionais.

No Brasil, os usos banalizados de Medida Provisória em quaisquer matérias, que é um instrumento com força de lei, adotado pelo presidente da República, em casos de relevância e urgência, tem despertado interesse e atenção dos juristas. Com a introdução do direito de laje ao rol dos direitos reais não foi diferente.

No entanto, a MPV n. 759, de 22 de dezembro de 2016, além de incluir o direito de laje, perseguia outros objetivos de alta relevância, pois instituía alterações na política de regularização fundiária rural e urbana. 
Com seu trâmite no Congresso Nacional, a MPV transformou-se em lei n. 13.465, em 11 de julho de 2017, oportunidade em que consolidou partes das reformas propostas por congressistas e especialistas na área de urbanismo, juristas e sociólogos, entre outros, para aquilo que seria o direito de laje.

Na prática, a inclusão do direito de laje como um direito real possibilitou a concretização e regularização do direito de moradia de centenas de pessoas que, em condições irregulares, passariam a ter meios adequados e legais de permitir o desmembramento da propriedade. Caberia ao proprietário de uma construção-base a faculdade de ceder a superfície superior ou inferior de sua construção para que o titular da laje mantenha unidade distinta daquela originalmente construída sobre o solo.

Neste estudo, pode-se observar que a natureza jurídica do direito de laje envolveu disputas de várias matrizes. Em parte, a forma como o direito civil opera suas classificações e subdivisões dogmaticamente contribuiu para as inúmeras divergências. Por outro lado, o direito de laje possui semelhanças com os institutos do direito de superfície e de condomínio edilício.

Essas semelhanças não foram suficientes para abarcar as complexidades que o instituto visava resolver e, nesse quadrante, foi apresentado as suas especificidades em diálogos com outras modalidades, sob os ditames do Código Civil de 2002 e do Estatuto da Cidade de 2001, além de analisar suas subespécies que guardam muitas semelhanças com o instituto da laje, mas que ainda não abrangem todas os pormenores que compõem esse novo direito, especialmente pela subordinação inerente ao direito superficiário incompatível com a potencialidade do direito autônomo de laje.

Outro instituto do direito real trazido à lume foi o condomínio edilício, em que também possui diversas similitudes com a laje, mas com ela não se confunde, especialmente pela simplicidade desse instituto imobiliário que não compatibiliza com todas as normas e exigências do condomínio.

Desse modo, resta declarar a distinção da laje de todos os institutos reais já previstos no diploma civilista vigente. O direito de laje é possui a natureza jurídica de um direito singular, sui generis, autônomo e independente da construção-base que a originou e possui um potencial ainda não delimitado. Esse foi o objetivo da lei n. 13.465/2017 ao atribuir ao instituto lajeário um caráter sui generis, pois atende mais prontamente às demandas sociais presentes no meio favelar urbano.

Todavia, ressalva-se a necessidade de uma legislação que traga mais pontos destoantes dos outros institutos aqui analisados, especialmente no tocante ao condomínio edilício ao qual possui dispositivos no diploma legal bastante semelhantes com os lajeários, até mesmo no que toca às áreas comuns.

Esse esforço normativo, além de possibilitar importantes mudanças sociais na regularização de inúmeras propriedades antes consideradas irregulares e sem acesso à inúmeras políticas de bem-estar e de moradia, torna o Brasil um dos pioneiros na disciplina de tal direito, diferente de tantos outros países que se limitam às interpretações doutrinárias.

\section{REFERÊNCIAS}

AFFE, Juliana. Direito de laje é reconhecido em ação de usucapião. Juiz de Direito de Pernambuco prolata a primeira sentença do país após a edição da Lei n. 13.465/2017. Disponível em: http://www.irib.org.br/noticias/detalhes/direito-de-laje-e-reconhecido-em- 
Direito de laje: da importância social e das controvérsias quanto ao direito de superfície e ao condomínio edilício

acao-de-usucapiao-juiz-de-direito-de-pernambuco-prolata-a-primeira- sentenca-do-pais. Acesso em: 07 abr. 2018.

AMARANTE, Fernanda Machado. O pluralismo jurídico e o direito de laje. Revista Jus Navigandi, ISSN 1518-4862, Teresina, ano 17, n. 3403, 25 out. 2012. Disponível em: https:// jus.com.br/artigos/22888. Acesso em: 19 fev. 2018.

AZEVEDO, Aluísio. O Cortiço. 1890. Disponível em: http://www.dominiopublico.gov.br/ download/texto/ua00021a.pdf. Acesso em: 26 fev. 2018.

BERNARDI, Jorge Luiz. Funções sociais da cidade: conceitos e instrumentos. 2006. 137f. Dissertação (Mestrado) Gestão Urbana. Pontifícia Universidade Católica do Paraná. Curitiba: PUC-PR, 2006.

BRASIL. Constituição Federal de 1988. Disponível em: http://www.planalto.gov.br/ ccivil_03/constituicao/constituicao.htm. Acesso em: 17 fev. 2018.

BRASIL. Estatuto da Cidade de 2001. Disponível em: http://www.planalto.gov.br/Ccivil_03/ leis/LEIS_2001/L10257.htm. Acesso em: 17 fev. 2018.

BRASIL. Código Civil de 2002. Disponível em: http://www.planalto.gov.br/ccivil_03/leis/ 2002/110406.htm. Acesso em: 17 fev 2018.

BRASIL. Medida Provisória $n^{0}$ 759. Cartilha de Esclarecimentos - regularização fundiária urbana e rural - Disponível em: http://www.mda.gov.br/sitemda/sites/sitemda/files/ user_arquivos_1763/CARTILHA\%20-\%20MP\%20759\%20-

\%20VERS\%2BO\%20FINAL.PDF. Acesso em: 22 fev 2018.

BRASIL. Medida Provisória no 759 de 2016. Disponível em: https:// www.congressonacional.leg.br/materias/medidas-provisorias/-/mpv/127879. Acesso em: 25 fev 2018.

BRASIL. Lei $\mathbf{n}^{\mathbf{0}} \mathbf{1 3 . 4 6 5}$ de 2017. Disponível em: http://www.planalto.gov.br/ccivil_03/ _ato2015-2018/2017/lei/113465.htm. Acesso em: 20 fev 2018.

BRASIL. Câmara dos Deputados. Deputado explica por que apoia a MP que prevê o "direito de laje". Disponível em http://www2.camara.leg.br/camaranoticias/tv/materias.html. Acesso em 21 fev 2018.

BRASIL. Tribunal de Justiça do Estado de Pernambuco. 26a Vara Cível da Comarca de Recife. Ação de Usucapião: Processos $n^{\circ}$ 0027691- 84.2013.8.17.0001 e 007137644.2013.8.17.0001, José Carlos da Silva E Luziana Pereira da Silva; Ladyane Carla de Araújo Silva, 2013.

CAMARGO, Marco Antônio de Oliveira. Direito de laje. Explicando para quem quer entender. $2017 . \quad$ Disponível em: http://www.notariado.org.br/ index.php?pG=X19leGliZV9ub3RpY2lhcw==\&in= OTA2MQ==. Acesso em 05 de abr de 2018.

CNJ - Conselho Nacional de Justiça. Enunciado $\quad \mathbf{n}^{\mathbf{0}}$ 487. Disponível em: http://www.cjf.jus.br/enunciados/enunciado/487. Acesso em 04 de abr de 2018.

CORREA, Cláudia Franco. Direito de laje: o direito na vida e a vida no direito. Anais do XVII Congresso Nacional do Conpedi. Brasília: Conpedi, 2008. Disponível em: http:// www.publicadireito.com.br/conpedi/manaus/arquivos/anais/brasilia/05_773.pdf. Acesso em 30 de jun. de 2011. 
DAMACENA, Fernanda Dalla Libera; WEBBER, Suelen. O direito de propriedade e a supremacia do interesse público sobre o privado na era de adapctação às mudanças climáticas. Revista Jurídica da FA7, Fortaleza, v. 13, n. 2, p. 55-70, jul./dez., 2016.

FARIAS, Cristiano Chaves de; DELBS, Martha El; e DIAS, Wagner Inácio. Direito de Laje. Salvador: Ed JusPodivm, 2017.

FERRARO, Valkíria A. Lopes. Direito de Superfície: Um Paralelo Entre o Estatuto da Cidade e o Novo Código Civil. Revista Jurídica da UniFil, Ano II - nº 2, 2005. Disponível em: http:// web.unifil.br/docs/juridica/02/Revista\%20Juridica_02-8.pdf. Acesso em 04 abr 2018.

FRANCESCHET, Júlio. O Condomínio Edilício sob a Perspectiva Civil-Constitucional. 2007. Disponível em: http://re.granbery.edu.br/artigos/MjA5.pdf. Acesso em: 05 de abr de 2018.

GUINSBURG, J.; FARIA, João Roberto (orgs.). O Naturalismo. São Paulo: Perspectiva, 2017.

LIRA, Ricardo Pereira. O Novo Código Civil, Estatuto da Cidade, Direito de Superfície. 2002a. Anais do “EMERJ Debate o Novo Código Civil”. Disponível em www.http:// www.emerj.tjrj.jus.br/revistaemerj_online/edicoes/anais_onovocod igocivil/anais_especial_2/ Anai s_Parte_II_revistaemerj_145.pdf Acesso em: 18 de fev 2018.

LIRA, Ricardo Pereira. $O$ estado social e a regularização fundiária como acesso à moradia. 2012. Disponível em: http://www.ablj.org.br/revistas/revista38e39.pdf. Acesso em 18 fev 2018.

LIRA, Ricardo Pereira. O Direito de Superfície e o Novo Código Civil. Revista Forense, Separata, vol. 364, $2002 \mathrm{~b}$.

LOUREIRO, Francisco Eduardo. Direito de Laje e superfície. 2017. http:// iregistradores.org.br/direito-de-laje-e-superficie/. Acesso em 05 de abr de 2018.

MAZZEI, Rodrigo. O direito de superfície no ordenamento jurídico brasileiro. Dissertação de Mestrado em Direito. São Paulo: PUC-SP, 2007.

MAZZEI, Rodrigo. O Direito de Superfície e a Sobrelevação (O Direito de Construir na Edificação Alheia ou "Direito de Laje". Revista Forense. Julho-Dezembro de 2012. Volume 416 - Ano 108.

MINISTÉRIO PÚBLICO DO ESTADO DE SÃO PAULO. Cartilha Regularização Fundiária Urbana. Disponível em: http://www.mpsp.mp.br/portal/page/portal/Cartilhas/2017\%20$\%$ 20Cartilha\%20regulariza\%C3\%A7\%C3\%A3o\%20fundi\%C3\%A1ria.pdf. Acesso em 06 mar 2018.

OLIVEIRA, Samuel Silva Rodrigues de. "Trabalhadores Favelados": identificação das favelas e movimentos sociais no Rio de Janeiro e em Belo Horizonte. Doutorado em História, Política e Bens Culturais. CPDOC - Fundação Getúlio Vargas. Rio de Janeiro: FGV, 2014.

PESSOA, Emanuel de Abreu. A constitucionalização da função social da propriedade: alteração na dogmática do Direito Civil. Revista Jurídica da FA7, Fortaleza, Vol. 7, número especial, p. 65-75, 2010.

PORTUGAL. Código Civil de 1966. Disponível em: http://www.stj.pt/ficheiros/fpstjptlp/ portugal_codigocivil.pdf. Acesso em: 18 fev de 2018. 
Direito de laje: da importância social e das controvérsias quanto ao direito de superfície e ao condomínio edilício

PEREIRA, Agnaldo Rodrigues. O Direito de Superfície, O "Direito de Laje" e o Reflexo no Direito Urbanístico. 2014. Disponível em: https://estudogeral.sib.uc.pt/bitstream/10316/ 28587/1/O\%20DIREITO\%20DE\%20SUPERFICIE.pdf. Acesso em: 08 de fev de 2018.

SANTOS, Boaventura de Sousa. Notas sobre a História Jurídico-Social de Pasárgada. 1973. Disponível em: http://www.geocities.ws/b3centaurus/livros/s/boavpassar.pdf. Acesso em: 04 mar 2018.

SARMENTO FILHO, Eduardo Sócrates Castanheira. O Direito de Superfície. Instituto de Registro Imobiliário do Brasil - IRIB. São Paulo, 2012.

STOLZE, Pablo. Direito Real de Laje: Primeiras impressões. 2017. Disponível em: http:// pablostolze.com.br/?s=laje. Acesso em: 20 de mar de 2018.

SUPPIA, Alfredo; SCARABELLO, Marília. "As reformas do Rio de Janeiro no início do século XX. Cidade é transformada para responder aos apelos do mundo que se moderniza" 2014. Disponível em: http://pre.univesp.br/as-reformas-do-rio-de-janeiro-no-inicio-doseculo- Xx\#.WsIcKYjwbIV>. Acesso em 02 de abr 2018.

TARTUCE, Flávio. Direito civil, v. 4: Direito das Coisas. Rio de Janeiro: Forense, 2016.

TESHIMA, Márcia; PONA, Everton Willian. Do Direito de Laje: Uma Visão Mitigada do Direito de Propriedade ao Direito à Moradia. Hiléia: Revista do Direito Ambiental da Amazônia, Manaus, n. 19, jan. jun., 2013, p. 215-250.

VILA, Marisa Iglesias. Las fuentes de indeterminación del derecho: una aproximación filosófica. Revista Jurídica da UFERSA, Mossoró, v. 2, n. 3, jan./jun., 2018, p. 21-47.

Recebido em: 10 jun. 2018. Aceito em: 4 nov. 2018. 